\begin{tabular}{|c|c|}
\hline Journal STAND: Sports and Development & http://jurnal.unipasby.ac.id/index.php/stand/about/submissions \\
unipa Sunabaya & jurnal.stand@unipasby.ac.id
\end{tabular}

\title{
HUBUNGAN ANTARA POWER TUNGKAI DAN KEKUATAN OTOT LENGAN TERHADAP KETEPATAN UNDERBASKET SHOOT
}

\author{
Suharti $^{1}$, M. Ilham Leksa Pambudi ${ }^{2}$ \\ Fakultas Keguruan dan Ilmu Pendidikan, Universitas PGRI Adi Buana Surabaya \\ email: atikpko@gmail.com ${ }^{1}$, Ilhamaja062@gmail.com²
}

\begin{tabular}{l}
\hline Artikel Info \\
\hline Koresponden penulis: \\
Suharti \\
Email. \\
atikpko@gmail.com \\
$\square$ Diterima 22 April 2020 \\
$\square$ Direview 12 Mei 2020 \\
$\square$ Disetujui 13 Mei 2020 \\
$\square$ Dipublikasi 27 Mei 2020
\end{tabular}

Kata Kunci:

Power tungkai, Kekuatan Otot

Lengan, Underbasket Shoot

Keywords:

Leg Power, Arm Muscle Strength,

Underbasket Shoot

\begin{abstract}
Abstrak
Penelitian ini bertujuan untuk mengetahui hubungan antara power tungkai dan kekuatan otot lengan dengan ketepatan underbasket shoot pada tim putra ekstrakulikuler bola basket SMA AL-Islam Krian. Metode yang digunakan pada penelitian ini yaitu kualitatif dengan teknik pengunpulan data menggunakan tes dan pengukuran. Populasi pada penelitian ini adalah tim putra pada ekstrakulikuler bola basket SMA AL-Islam Krian yang berjumlah 40 siswa. Sampel yang diambil menggunakan teknik purposive sampling, dengan kriteria yaitu : (1) tim putra bola basket ekstrakulikuler SMA AL-Islam Krian. (2) merupakan tim bola basket yang memenuhi kriteria berjumlah 20 orang. Instrumen yang digunakan adalah power tungkai diukur dengan menggunakan tes vertical jump dengan satuan centimeter. Kekuatan otot lengan diukur dengan pull up test menggunakan satuan kilogram. Tembakan underbasket menggunakan underbasket shoot per menit. Analisis data menggunakan uji regresi korelasi. Hasil analisis menunjukkan (1) adanya hubungan antara power tungkai dengan ketepatan underbasket shoot pada tim putra ekstrakulikuler bola basket dengan nilai $\mathrm{r} x 1 . \mathrm{y}=0.485>\mathrm{r}(0,05)(20)=0.444$ (2) adanya hubungan antara kekuatan otot lengan dengan ketepatan underbasket shoot pada tim putra bola basket dengan $\mathrm{r} \times 2 . \mathrm{y}=0.510>\mathrm{r}(0.05)(20)=0.444$.
\end{abstract}

\begin{abstract}
This study aims to determine the relationship between leg power and arm muscle strength with the accuracy of the underbasket shoot on the men's basketball extracurricular team at AL-Islam Krian High School. The method used in this study is qualitative with data collection techniques using tests and measurements. The population in this study was the men's team at the Krian AL-Islam High School basketball extracurricular totaling 40 students. Samples were taken using a purposive sampling technique, with the following criteria: (1) the extracurricular basketball men's team at the AL-Islam Krian High School. (2) a basketball team that meets the criteria of 20 people. The instrument used was leg power measured using a vertical jump test in centimeters. Arm muscle strength is measured by pull up test using units of kilograms. Underbasket shots use underbasket shoot per minute. Data analysis using correlation regression test. The results of the analysis show (1) there is a relationship between leg power and the accuracy of shoot underbasket in the men's basketball extracurricular team with a value of $\mathrm{r}$ x1.y $=$ $0.485>\mathrm{r}(0.05)(20)=0.444$ (2) there is a relationship between arm muscle strength with the accuracy of the shoot underbasket on the men's basketball team with r x2.y $=0.510>$ r $(0.05)(20)=0.444$.
\end{abstract}




\begin{tabular}{|c|c|c|}
\hline Journal STAND: Sports and Development & http://jurnal.unipasby.ac.id/index.php/stand/about/submissions \\
unipa Sumalayg & jurnal.stand@unipasby.ac.id
\end{tabular}

\section{PENDAHULUAN}

Olahraga merupakan aktivitas yang sangat populer, baik di Indonesia maupun di luar Indonesia. Olahraga juga dapat sebagai sarana untuk kebugaran tubuh baik jasmani atau rohani dan juga dapat menjadi sarana pemersatu bangsa. dengan adanya banyak kegiatan olahraga, di Indonesia sendiri banyak kegiatan olahraga yang digelar, seperti yang marak diadakan dikalangan remaja ataupun umum, salah satunya adalah event bola basket remaja seperti DBL dan event bola basket mahasiswa seperti campus league dan LIMA (liga mahasiswa) dengan adanya banyak event itu dapat meningkatkan pembinaan bola basket bagi pemula sampai professional.

Dengan demikian akan banyak atlet yang harus menguasai banyak teknik dasar dalam bermain bola basket dengan baik dan benar agar dapat bersaing di event - event nasional.

Bola basket merupakan cabang olahraga yang makin banyak digemari oleh masyarakat terutama dikalangan pelajar dan mahasiswa. Sedangkan Menurut Danny Kosasih (2008:2) "bola basket adalah permainan yang menggunakan kecepatan (kaki dan tangan) dalam waktu yang tepat. Hal tersebut harus dilatihkan saat mengembangkan serta melatih skill individu pemain, fisik,emosi dan team balance, baik dalam posisi defense maupun offense".

Dalam permainan bola basket ada beberapa teknik dasar yang harus dikuasai dan dimiliki oleh seorang pemain, menurut Nuril
Ahmadi (2007: 13) ada beberapa teknik dasar (fundasmentals) yaitu teknik dasar mengoper bola (Passing), teknik dasar menerima bola, teknik dasar menggiring bola (dribbling), teknik dasar menembak (shooting), teknik latihan olah kaki (footwork), teknik latihan pivot. Dari beberapa macam teknik tersebut teknik dasar shoot (menembak) merupakan teknik yang paling penting dan utama untuk mencetak poin. Agus Salim (2008: 61) mengungkapkan bahwa, "kalian selamanya tidak akan bisa mencetak angka, kecuali kalian telah dapat melakukan teknik menembak“. Jadi didalam sebuah permainan bola basket, shooting (menembak) adalah teknik yang terpenting karena merupakan salah satu cara yang sering mencetak angka.

Tujuan utama dari permainan bola basket adalah untuk dapat menciptakan peluang tembakan yang tepat sasaran dan dapat memperoleh angka pada setiap peluang menembak dengan sebanyak mungkin,itu merupakan syarat tim dapat dinyatakan sebagai pemenang. Menurut pendapat Machfud Irsyada (2000:14), bahwa sesuai dengan tujuan utama permainan bola basket itu sendiri yaitu memasukan bola sebanyak mungkin ke keranjang lawan dengan cara yang sportif sesuai dengan aturan yang telah disepakati. Regu yang dapat mencatat atau mencetak angka (score) paling tinggi adalah sebagai pemenang. Menurut Hal Wissel (1996:43) menembak adalah keahlian yang sangat penting dalam permainan bola basket dan sangat penting untuk dikuasai secara baik, akan tetapi tidak boleh 


\begin{tabular}{|c|c|}
\hline Journal STAND: Sports and Development \\
unipa Sumalama
\end{tabular} $\begin{gathered}\text { htt//jurnal.unipasby.ac.id/index.php/stand/about/submissions } \\
\text { jurnal.stand@unipasby.ac.id }\end{gathered}$

mengesampingkan ketrampilan gerak dasar yang lainnya.

\section{KAJIAN LITERATUR DAN PEGEMBANGAN HIPOTESIS}

Menurut Hal Wissel (2000: 67), underbasket Shoot adalah menembak dari sudut 45 derajat dari setiap arah ke keranjang. Mulai dengan sikap seimbang pada sudut 45 derajat dengan papan yaitu, jarak antara kotak dan tengah-tengah pada lane. Jarak tepi sudut melebar ketika anda bergerak keluar disebut (45 degree funnel/ cerobong 45 derajat). Teknik underbasket shoot ini sangatlah sering digunakan dalam permainan bola basket dengan presentase memasukan bola ke ring basket yang lebih besar, karena dilakukan dengan dengan lompatan. Gerakan tersebut juga memerlukan power atau unsur kondisi fisik yang dibutuhkan karena hamper semua cabang olahraga menggunakan power.

Menurut Mulyono, (1997: 54) power adalah hasil kali kekuatan dan kecepatan. menyatakan bahwa power adalah kemampuan yang untuk mengerahkan kekuatan maksimum dalam waktu yang sesingkat-singkatnya. Kekuatan sendiri adalah kemampuan otot untuk membangkitkan tegangan terhadap suatu tahanan (Harsono,1988:176). Otot yang kuat akan membuat kerja otot lebih efisien saat melakukan olahraga. Oleh karena itu apabila dalam permainan bola basket pemain yang akan melakukan underbasket shoot tidak memiliki power yang bagus maka pemain akan mengalami masalah, apabila lawan memiliki power yang lebih bagus pemain akan kalah dalam berhadapan dan pada saat melakukan underbasket shoot akan terkena block oleh lawan.

Shooting merupakan salah satu kunci utama dalam kemenangan tim (Yandika,2016). Kemenangan tim dipengaruhi dengan jumlah berhasilnya tembakan yang dilakukan, meskipun tidak meninggalkan teknik dasar lainya. Menurut Dedy Sumiryaso (2002: 23) ada beberapa cara menembak diantaranya yaitu: straight Turn Shoot Underbasket,Shoot Underbasket, The Hook Shoot,the Helf Hook Shoot, Two Hand Under Hand Sweep Shoo dan One Hand Under Hand Sweep Shoot. Underbasket shoot adalah salah satu teknik dasar yang harus di kuasai dan di miliki oleh pemain bola basket. Karena dalam teknik ini juka tidak dikuasai berpengaruh terhadap teknik lain seperti layup. seperti yang diungkapkan oleh Jon Oliver (2007: 13), "Semakin dekat dengan ring basket, semakin besar kesempatan untuk melakukan tembakan“. Artinya apabila pemain melakukan shoot semain dekat dengan ring basket, maka pemain tersebut berpeluang besar untuk melakukan tembakan. Semakin dekat dengan ring basket semakin besar peluang menciptakan angka.

\section{METODE PENELITIAN}

Penelitian ini termasuk ke dalam bentuk penelitian korelasional. Penelitian korelasional merupakan sebuah bentuk penelitian yang dilaksanakan agar dapat mengetahui ada atau 


\begin{tabular}{|c|c|}
\hline Journal STAND: Sports and Development \\
unipa Sumalama
\end{tabular} $\begin{gathered}\text { htt//jurnal.unipasby.ac.id/index.php/stand/about/submissions } \\
\text { jurnal.stand@unipasby.ac.id }\end{gathered}$

tidaknya suatu hubungan di antara kedua atau lebih dari beberapa variabel (Suharsimi Arikunto, 2002: 247). Dalam penelitian ini metode yang dipergunakan ialah dengan menggunakan survei dengan Teknik pengumpulan data menggunakan sebuah tes dan pengukuran. . Instrumen yang digunakan adalah pengukuran kekuatan power tungkai diukur dengan menggunakan tes vertical jump dengan satuan centimeter dan pengukuran kekuatan otot lengan diukur dengan pull up test menggunakan satuan kilogram. Tembakan underbasket menggunakan underbasket shoot per menit. Analisis data menggunakan uji regresi korelasi.

\section{HASIL DAN PEMBAHASAN}

Penelitian ini bertujuan agar dapat mengetahui hubungan antara power tungkai dan kekuatan otot tungkai terhadap hasil underbasket shoot pada tim putra ekstrakulikuler bola basket SMA AL-Islam Krian. Hasil dari pembahasan masing-masing variabel dapat dilihat sebagai berikut :

\section{Hubungan Power tungkai dengan} underbasket shoot

Hasil analisis menunjukkan bahwa ada hubungan yang signifikan antara power tungkai dengan hasil underbasket shoot pada tim putra ekstrakulikuler bola basket SMA AL-Islam Krian, dengan nilai $r_{X 1 . y}=0,485>r(0.05)(20)=$ 0,444 yang artinya koefisien korelasi tersebut signifikan. Power tungkai merupakan kekuatan yang dikeluarkan secara maksimal yang akan digunakan dalam waktu yang singkat. Power tungkai merupakan salah satu komponen fisik yang harus dimiliki oleh para pemain. Power adalah kemampuan otot atau sekelompok otot seseorang untuk menggunakan kekuatan semaksimal mungkin yang dikerahkan dalam waktu yang sependek-pendeknya.

Power tungkai mempunyai peran yang besar terhadap keberhasilan melakukan underbasket shoot, karena kaki adalah dasar keseimbangan dan menjaga kepala agar tetap segaris dengan kaki sebagai kontrol keseimbangan. Selain itu tekukkan kaki akan memberikan tenaga penting untuk tembakan, pemain yang sudah kecapaian sering gagal menekuk lututnya hingga kekurangan tenaga untuk melontarkan bola dengan kaki. Pada saat melakukan underbasket shoot perlu juga untuk memperhatikan BEEF (Balance, Eye, Elbow, Follow Trought) dan konsentrasi pada saat melakukannya.

2. Hubungan Kekuatan Otot Lengan dengan Underbasket Shoot

Hasil analisis menunjukkan jika ada hubungan yang tidak signifikan antara kekuatan otot lengan dengan hasil underbasket shoot pada tim putra ekstrakulikuler bola basket SMA ALIslam Krian dengan nilai $\mathrm{r}_{\mathrm{x} 2 . \mathrm{y}}=0,510>$ $\mathrm{r}(0.05)(20)=0,444$, berarti koefisien korelasi tersebut signifikan.

Kekuatan (strength) merupakan salah satu komponen dasar biomotor yang diperlukan dalam setiap cabang olahraga“. Artinya kekuatan merupakan faktor yang penting karena merupakan komponen dasar biomotor. Kekuatan 


\begin{tabular}{|c|c|}
\hline Journal STAND: Sports and Development \\
unipa Sunalaya
\end{tabular} $\begin{gathered}\text { http://jurnal.unipasby.ac.id/index.php/stand/about/submissions } \\
\text { jurnal.stand@unipasby.ac.id }\end{gathered}$

otot yang dimaksud penulis yaitu kemampuan otot lengan dalam mempergunakan otot-ototnya pada saat menerima beban dalam waktu kerja tertentu. Kekuatan otot lengan disini yaitu kemampuan seseorang dalam menggunakan sekelompok otot agar dapat melakukan gerakan mendorong. Apabila dalam melakukan permainan bola basket, para pemain yang akan melakukan underbasket shoot dapat melakukannya tanpa kekuatan otot lengan berlebih. Cukup dengan melecutkan bola ke papan pantul ring dengan menggunakan konsep yang sama seperti power tungkai yaitu $B E E F$ (Balance, Eye, Elbow, Follow Trought) dan tetap melakukannya dengan konsentrasi.

\section{KESIMPULAN}

Berdasarkan hasil analisis data, deskripsi, pengujian hasil penelitian, dan pembahasan, dapat diambil kesimpulan bahwa adanya hubungan antara power tungkai dengan hasil underbasket shoot pada tim putra ekstrakulikuler bola basket SMA AL-Islam Krian, dengan nilai $r_{X 1 . y}=0,485>r(0.05)(20)=0,444$. Serta Ada pula hubungan antara kekuatan otot lengan dengan hasil underbasket shoot pada tim putra ekstrakulikuler bola basket SMA AL-Islam Krian, dengan nilai $\mathrm{r}_{\mathrm{X} 2 . \mathrm{y}}=0,510>\mathrm{r}_{(0.05)(20)}=$ 0,444 .

\section{REFERENSI}

Agus Salim. (2008). Buku Pintar Bola Basket. Bandung: NUANSA
Arinto 2014. Pengaruh Latihan Kelincahan Terhadap Kemampuan Mendribble Bola Pada Siswa SMP Negeri 1 Gedangan Sidoarjo. Skripsi Sarjana Pendidikan: Universitas PGRI Adi Buana Surabaya.

Danny Kosasih. (2008). Fundamental Basketball. Semarang: Karang Turi Media.

Dwi Febriansyah. (2011). Hubungan Kecepatan Reaksi, Daya Ledak Otot Tungkai ,dan Kekuatan Otot Tungkai Terhadap Start Renang Gaya Dada menggunakan Grap Start. Skripsi. Yogyakarta: FIK UNY.

Nana Syaodih. (2011). Metode penelitian pendidikan. Bandung: PT. Remaja Rosdaka.

Nugroho, Fadli. (2014). Hubungan Daya Ledak (Power) Otot Tungkai dengan Kemampuan Jump Shoot pada Permainan Bola Basket di SMP Negeri 1 Curup Timur. Bengkulu

Nurhasan. 2010. Tes dan Pengukuran Pendidikan Olahraga. Bandung; Penerbit Universitas Pendidikan Bandung.

Ngatman. (2001). Tes Dan Pengukuran. Yogyakarta: FIK UNY.

Maksum Ali (2012). Metodologi Penelitian dalam Olahraga. Surabaya: Unesa University Press

Oliver, Jon. (2007). Basketball Fundamentals (Dasar-dasar Bola Basket). Penerjemah: Wawan Eko Yulianto,S.S. Bandung: PT Intan Sejati.

Suharsimi Arikunto. (2002). Prosedur Penelitian Suatu Pendekatan Praktek. Jakarta: Rhineka Cipta.

Yandika FR. (2016). Kontribusi Power Otot Tungkai, Persepsi Kinestetik Dan Koordinasi Mata Tangan Terhadap Keberhasilan Tembakan Lompat (Jump Shoot) Bolabasket. Buana Pendidikan: Jurnal Fakultas Keguruan dan IImu Pendidikan, 12 (22), 135-157. 